\title{
A Study on Learning Motives and Learning Effects of Vocational High School Students to Energy Technology Education Integrated into Project Course
}

\author{
Fang-Pin Lai, Chin-Wen Liao, Chia-Ling Shih, and Chin-Chang Wu
}

\begin{abstract}
This study aims at discussing the correlation between the learning motivation and effect of public partial high school students majoring in electrical engineering and electronics as integrating project implementation course into energy science education. The result of this study is as following: public partial high school students majoring in electrical engineering and electronics have higher learning motivation when it comes to the aspect of "interest in knowledge-seeking" as integrating project implementation course into energy science education; they have higher learning effect when it comes to the aspect of "recognition" as integrating project implementation course into energy science education. Among them, those who selected "entering to a higher school," "projects being relevant" and "having the will to take part in contests" among the context variables have higher learning motivation and effect. As a result, there is an obvious positive correlation between their learning motivation and effect.
\end{abstract}

Index Terms-Energy science education, project implementation course, learning motivation, learning effect.

\section{INTRODUCTION}

Energy is a significant resource for humans to survive on; the development history of human civilization is closely related with the energy humans use. According to the information from the energy statistical data book [1], 97.93\% of the energy in Taiwan depends on import. Thus, in the society that technology changes with each passing day; in the condition that the lack of energy gets worse, we have no choice but to pay close attention to the problems. Under the historical background, Taiwan has created many economic miracles, yet behind those economic miracles, the cost we have paid is the destruction of land resources and ecological environment. According to Taiwan Climate Change Report [2], in the previous hundred years ago (1906 2005), the temperature of the atmosphere near the ground had increased about $0.74^{\circ} \mathrm{C}$, and the sea level had risen about $77 \mathrm{~mm}$ from 1961 to 2003. The annual mean temperature in Taiwan had risen from 1911 to 2009 , meaning that the rate of temperature increase was equivalent with increasing $0.14^{\circ} \mathrm{C}$ per ten years, higher than the global mean (increasing $0.074^{\circ} \mathrm{C}$ per ten years). Therefore, only if we controlled the continual increase of carbon dioxide and the other greenhouse gases could we lower the global warming effect. To slow down the global

Manuscript received April 8, 2014; revised June 15, 2014.

The authors are with the Department of Industrial Education and Technology at National Changhua University of Education (NCUE), Taiwan (e-mail: lion0829@gmail.com, tcwliao@cc.ncue.edu.tw, malisa168@yahoo.com.tw,wcc1102@yahoo.com.tw). climate change caused by the greenhouse gases released during human activities, the United Nations passed the "United Nations Framework Convention on Climate Change" in 1992, making an international treaty to prevent and control the emissions of "man-made greenhouse gases." In December 1997, the United Nations held a conference in Kyoto, Japan, and passed Kyoto Protocol to bind industrialized countries to reduce emissions of greenhouse gases from 2008 to 2012 until the mean emission was equal to that in 1990 minus 5.2\%. Thanks to the support from industrialized countries in European Union, Kyoto Protocol was brought into effect on February 16th, 2005, and climate change would become the global prior issue [3].

Taiwan government passed "Energy Continuity Guidelines" on June 5th, 2008, announcing clearly the goal to reduce carbon dioxide - regressing to the mean emission of 2008 between 2016 and 2020, regressing to the mean emission of 2000 in 2025, regressing to half the mean emission of 2000 in 2050 [4]. During the Energy Conference in 2009 , the goal to "establish low-carbon homeland" within ten years was suggested. Environmental Protection Administration, Executive Yuan had planned and advanced the solid goal and schedule to establish "low-carbon communities," "low-carbon cities" and "low-carbon living areas" within ten years, uniting local governments to advance carbon-reducing towns, finishing establishing two low-carbon model communities in every city and county in 2011 (fifty low-carbon model communities in total), advancing six low-carbon cities in 2014, and finishing establishing four low-carbon living areas in northern, central, southern and eastern Taiwan [5].

Taiwan government announced the new energy policy about reducing nuclear power step by step in November 2011 . According to the new energy policy, Taiwan would increase the development and usage of clean energy (renewable energy and natural gas). Yet, in Taiwan, besides wind power and hydroelectricity, petroleum, natural gas, coal and uranium all depend on import. As the price of international energy rises, in addition to actively developing renewable energy, the goal to "save energy" and "reduce carbon" should be set, and strengthen the extension and guidance of energy science education, in order to promote the energy usage efficiency, reduce energy cost, and improve the overall competitiveness. So far, starting with daily life, the government has been actively advancing the work to save energy and practicing the policy of energy-saving and carbon reduction; this is the most effective way. In fact, practicing and advancing "energy science education" on site is the most fundamental and effective working direction. 
The target of energy science education has long been junior high school and elementary school students that are beginning to experience socialization, neglecting the continual education of senior high school and partial high school students [6]. In 2008, in the program of guiding schools to promote energy, Bureau of Energy, Ministry of Economic Affairs set the rule of raising energy literacy in junior high school and elementary school to practice and creative development of energy in senior high school and partial high school, establishing key schools with energy science education, and holding energy-saving competitions for senior high school and partial high school students, in order to save energy. "Ministry of Education's National Science Technology Program-Energy" also established senior high school and partial high school energy science education promoting centers, and held "energy science creativity competitions", so as to extend the energy science education from junior high schools and elementary schools to senior high schools and partial high schools, moving toward a new milestone. However, the participants of research on energy science education are mostly junior high schools and elementary schools, lacking senior high schools and partial high schools. This is the first motive of this study.

Owing to global warming and climate change, to reduce emissions of greenhouse gases has become the consensus of every country. According to the statistics of emissions of carbon dioxide by burning energy published by IEA/ OECD (Environmental Protection Administration, Executive Yuan, 2013b) [7], the emissions of carbon dioxide by burning energy in Taiwan in 2010 was 270.22 million tons, which accounts for $0.89 \%$ in global emissions, ranking top 20 in the world; the mean emissions of carbon dioxide per person was 11.66 tons, ranking top 19 in the world (ranking top 10 in Asia). To reach the goal to save energy and reduce carbon, only by thoroughly advancing energy science education can achieve "sustainable development." This is the second motive of this study.

\section{OBJECTIVE}

1) Discussing the status quo of advancing integrating project implementation course into energy science education in public senior high schools and partial high schools.

2) Comparing the differences of learning motivation of public partial high school students majoring in electrical engineering and electronics as integrating project implementation course into energy science education due to different context variables.

3) Comparing the differences of learning effect of public partial high school students majoring in electrical engineering and electronics as integrating project implementation course into energy science education due to different context variables.

4) Discussing the relevant conditions between learning motivation and effect of public partial high school students majoring in electrical engineering and electronics as integrating project implementation course into energy science education.

\section{METHODS}

This study mainly discusses the learning motivation and effect of public partial high school students majoring in electrical engineering and electronics as integrating project implementation course into energy science education. I collected documents and designed the "questionnaire of the learning motivation and effect of public partial high school students majoring in electrical engineering and electronics as integrating project implementation course into energy science education" as the research tool. By using questionnaire investigation to collect relevant data to calculate and analyze them, I brought up the discovery of this study.

According to the discussion of relevant theories and documents, this study surveys relevant factors that influence public partial high school students majoring in electrical engineering and electronics as integrating project implementation course into energy science education, gathering and summing up the correlation between relevant variables. The variables include independent variables (students' context variables) and dependent variables (learning motivation and effect included). Their contents are as following:

\section{A. Independent Variables}

1) Geographical location of schools: 1) north, 2) central, 3) south, 4) east

2) Prospects after graduation: 1) entering to a higher school, 2) obtaining employment

3) Relevance between the topic of project implementation courses and energy science education: 1) relevant, 2) irrelevant

4) Will to take part in project implementation competitions: 1) yes, 2) no

5) Having taking part in project implementation competitions or science fairs: 1) no, 2) yes

\section{B. Dependent Variables}

1) Learning motivation: 1) interest in knowledge-seeking, 2) value of the subject, 3) career development, 4) expectation of success

2) Learning effect: 1) affection, 2) recognition, 3) skills

\section{Participants}

The populations of this study consist of third grade Day Division students majoring in electrical engineering and electronics in public partial high school all over the country. I utilized stratified random sampling to conduct the questionnaire investigation — taking samples randomly from each stratum, northern Taiwan (Yilan County, Keelung City, Taipei City, New Taipei City, Taoyuan City, Hsinchu County, Hsinchu City), central Taiwan (Miaoli County, Taichung City, Nantou County, Changhua County, Yunlin County), southern Taiwan (Chiayi County, Chiayi City, Tainan City, Kaohsiung City, Pingtung County), and eastern Taiwan (Hualien County, Taitung County), and then taking school as the sampling unit, selecting thirteen schools (four from northern Taiwan, four from central Taiwan, four from southern Taiwan, and one from eastern Taiwan) to perform the questionnaire test. 


\section{Research Tools}

The researcher designed the "questionnaire of the learning motivation and effect of public partial high school students majoring in electrical engineering and electronics as integrating project implementation course into energy science education" as the foundation of data collection; its main content includes three parts: 1) student information form, aimed at knowing students' background information, 2) learning motivation scale, for discussing the aspect of the learning motivation of partial high school students majoring in electrical engineering and electronics as integrating project implementation course into energy science education, 3) learning effect scale, for researching the learning effect of partial high school students majoring in electrical engineering and electronics as integrating project implementation course into energy science education.

\section{1) Designing the first draft of the questionnaire}

After I finished designing the first draft of the questionnaire and asked the adviser to read it for the first time and revise it, I invited three college professors who are experts in vocational education and four representatives who teach project implementation to give some opinions about revising the title of the questionnaire, word usage, etc. so as to establish the content validity of the research tools and use it as the important reference to revising the formal questionnaire. The expert scholars checked question by question according to the propriety, and picked one from the options of "propriety," "applicable revision," "deletion" and "opinions of revision" under each question; if they thought something needed revising, they would filling out the comment column about their opinions of revision. Then, I collected and reorganized the first drafts, designing the preliminary questionnaires.

\section{2) Performing the preliminary questionnaires}

After the completion of the draft questionnaire prepared, it's necessary to pre-run the draft questionnaire instantly for knowing its adaptability and usability. Thus, the pre-run questionnaires were sent in April 10, 2013. The pre-run objects in this research, principled by purposive sampling, are 40 students from "Dept. of Electrical Engineering" of National Dajia Industrial Senior High School, 40 students from "Electronics Department" of Wufen Agricultural and Industrial Vocational High school, 40 students from "Electronics Department" of National Taichung Industrial High School, 40 students from "Dept. of Electrical Engineering" of National Erh-lin Industrial and Commercial Vocational High School respectively. After two weeks, we withdrew 152 valid pre-run questionnaires from 160 sent questionnaires; the effective response rate was up to $95 \%$.

In order to assure the research of reliability and validity, we used statistical software to proceed Item Analysis, Factor Analysis, and Cronbach's $\alpha$ Coefficient Test (Cronbach's $\alpha$ ). After testing the reliability and validity of the questionnaires, then we developed a formal questionnaire.

\section{a) Item analysis}

There were 26 questions in the pre-run questionnaire "Learning Motivation Scale". The questions probed into 4 aspects including 'Learning Desire', 'Disciplinary Value',
'Career Progress', and 'Expectations of Success'. After the SPSS statistical analysis, we found that the reliability and validity are high except the Question 4, whose Pearson's correlation coefficient is less than .400 .

There were 24 questions in the pre-run questionnaire "Learning Outcomes Scale". The questions probed into 3 aspects including 'Affection', 'Cognition', and 'Skills'. Independent sample t-test showed that all questions in the scale fit in with $p<.05$, which means the scale has discrimination. The Cronbach's $\alpha$ value of the scale is .955 , above the average value, which means it has good reliability. In the homogeneity teat, the Pearson's correlation coefficient is above .499 , showing high correlation, which means that it has good homogeneity. Overall, the "Learning Outcomes Scale" completely conform to statistical requirements; thus, the scale are all reserved.

\section{b) Factor analysis}

After going through the Item Analysis, we then proceeded to Factor Analysis. We utilized Principal Components Analysis to extract factors of all the reserved questions. Then, we utilized The Maximum Variation Method to conduct orthogonal rotation, analyzing the common factors. Finally, we used the standard of eigen value whose value must more than 1 to find out what aspect every question belongs to, and name for the aspects.

We called the factor 1 as 'Skills', the factor 2 as 'Affection', and the factor 3 as 'Cognition'.

\section{c) Reliability analysis}

For knowing the reliability of the questionnaire further, we needed to proceed Reliability Analysis after the Item Analysis and the Factor Analysis. We tested the internal consistency of the scale by Cronbach's Coefficient. According to $\mathrm{Wu}[8]$, he integrated everyone's viewpoints, considering that the $\alpha$ Coefficient of the normal attitude or psychological perception scale should be over .70. That means the internal constituency and reliability of the questionnaire is great.

The $\alpha$ Coefficient in the overall scale and subscales of the "Learning Motivation Scale" are all greater than .70. The $\alpha$ Coefficient in the overall scale is .948 , and the $\alpha$ Coefficient in the four subscales are $.915, .908, .891, .754$ respectively.

The $\alpha$ Coefficient in the overall scale and subscales of the "Learning Outcomes Scale" are all greater than .70. The $\alpha$ Coefficient in the overall scale is .948 , and the $\alpha$ Coefficient in the three subscales are $.945, .912, .822$ respectively.

From those $\alpha$ Coefficient, we can find that after deleting the question, the overall scale and the subscales have good internal constituency.

\section{ANALYZING AND DisCUSSING THE DATA}

In this section, we will discuss the results of the literature review and research the results of the statistical data analysis. Firstly, we will probe into the variable analysis of students' background. Secondly, we will then probe into the analysis of current situation where the students of Electrical and Electronics Department in vocational high school's learning motivation and outcomes as energy science education is integrated with monographic topics. 


\section{A. The Variable Analysis of Students' Background}

1) School Location: There are 276 students studying in Northern Taiwan, making up 33\% of valid sampling; 265 students studying in Central Taiwan, making up $32.4 \%$ of valid sampling; 277 students studying in Southern Taiwan, making up $33.9 \%$ of valid sampling. That reveals that the sampling is evenly distributed to the northern, central, southern schools.

2) The Future Direction after Graduation: There are 766 students choosing to go for further study after graduating from vocational high school, making up $93.6 \%$ of valid sampling; 52 students choosing to get a job after graduating from vocational high school, making up 6.4\% of valid sampling. That reveals that the majority of students want to go for further study after graduation.

3) The Correlation between Monographic Topics and Energy Science Education: In the 818 valid questionnaires, there are 391 students whose monographic topics are related to energy science education, making up $47.8 \%$ of valid sampling; 427 students whose monographic topics are not related to energy science education, making up $52.2 \%$ of valid sampling. The percentage of the correlation between monographic topics and energy science education is almost 50\%. From the statistics, we can know that energy science education is getting more and more respects in the industrial and academic profession.

4) The Willingness of Taking Part in Monographic Producing Competition: In the 818 valid questionnaires, there are 382 students who are willing to take part in the monographic producing competition, making up $46.7 \%$ of valid sampling; 436 students who are not willing to take part in the monographic producing competition, making up $53.3 \%$ of valid sampling. The statistics shows that the percentage of students' willing to participate in monographic producing competition is about $50 \%$.

5) The Experiences of Taking Part in Monographic Producing Competition or Science Exhibition: In the 818 valid questionnaires, there are 610 students who have no experience in taking part in the monographic producing competition or science exhibition, making up $74.6 \%$ of valid sampling; there are 208 students who have the experience of taking part in the monographic producing competition or science exhibition, making up $25.4 \%$ of valid sampling. The statistics shows that the percentage of students' having experiences in taking part in the monographic producing competition or science exhibition is about $25 \%$.

TABLE I: THE ANALYSIS OF VARIANCE OF STUDENTS BACKGROUND VARIABLES IN STUDENTS' CURRENT LEARNING MOTIVATION SiTUATION

\begin{tabular}{|c|c|c|c|c|c|}
\hline Name & School Location & $\begin{array}{c}\begin{array}{c}\text { Future Direction after } \\
\text { Graduation }\end{array} \\
\end{array}$ & $\begin{array}{c}\text { Monographic } \\
\text { Correlation }\end{array}$ & $\begin{array}{l}\text { Willingness of Taking } \\
\text { Part in Competition }\end{array}$ & $\begin{array}{l}\text { Competition } \\
\text { Experiences }\end{array}$ \\
\hline Career Progress & - & $(1)>(2)$ & $(1)>(2)$ & $(1)>(2)$ & - \\
\hline Expectations of Success & - & $(1)>(2)$ & $(1)>(2)$ & $(1)>(2)$ & - \\
\hline Disciplinary Value & - & $(1)>(2)$ & $(1)>(2)$ & $(1)>(2)$ & - \\
\hline Learning Desire & - & $(1)>(2)$ & $(1)>(2)$ & $(1)>(2)$ & - \\
\hline $\begin{array}{l}\text { The Overall Learning } \\
\text { Motivation }\end{array}$ & - & $(1)>(2)$ & $(1)>(2)$ & $(1)>(2)$ & - \\
\hline
\end{tabular}

A. School Location: a. In Northern Taiwan, b. In Central Taiwan, c. In Southern Taiwan;

B. Future Direction after Graduation: a. Go for further study, b. Get a job;

C. Monographic Correlation: a. Related, b. Unrelated

D. Willingness of Taking Part in Competition: a. Willingness, b. Unwillingness;

E. Competition Experiences: a. No, b. Yes.

The analysis of current situation where students' learning motivations as energy science education is integrated with monographic topics. We will archive the statistical analysis results in Table I.

1) The Analysis of Variance of Students from Different School Location's Different Learning Motivations. Students from different school location have little difference in 'Career Progress', 'Expectations of Success', 'Disciplinary Value' , 'Learning Desire' and 'The Overall Learning Motivation'. That shows that students from different school location have similar learning motivations; students' learning motivations would not be different because of the school locations.

2) The Analysis of Variance of Students with Different Future Direction after Graduation's Different Learning Motivations. Students with different future direction after graduation in 'Career Progress', 'Expectations of Success', 'Disciplinary Value' , 'Learning Desire', 'The Overall Learning Motivation', and some other aspects all shows that students who choose to go for further study after graduation have higher learning motivations than those who choose to get a job after graduation.

3) The Analysis of Variance of Students with Different
Monographic Correlation's Different Learning Motivations. Students with different monographic correlation in 'Career Progress', 'Expectations of Success', 'Disciplinary Value', 'Learning Desire', 'The Overall Learning Motivation', and some other aspects all shows that students whose monographic topics are related to energy science education have higher learning motivations than those whose monographic topics are not related to energy science education.

4) The Analysis of Variance of Students with Different Willingness of Taking Part in Monographic Producing Competition's Different Learning Motivations. Students with different willingness of taking part in monographic producing competition in 'Career Progress', 'Expectations of Success', 'Disciplinary Value', 'Learning Desire', 'The Overall Learning Motivation', and some other aspects all shows that students who are willing to join the competition have higher learning motivations than those who aren't willing to join the competition.

5) The Analysis of Variance of Students with Different Experiences of Taking Part in Monographic Producing Competition or Science Exhibition's Different Learning 
Motivations. Students with different competition experiences have little difference in 'Career Progress', 'Expectations of Success', 'Disciplinary Value' , 'Learning Desire' and 'The Overall Learning Motivation'.
The Analysis of Current Situation where students' learning outcomes as energy science education is integrated with monographic topics. We will archive the statistical analysis results in Table II.

TABLE II: THE VARIANCE ANALYSIS OF STUDENTS’ BACKGROUND VARIABLE IN PRESENT EFFICIENCY

\begin{tabular}{|c|c|c|c|c|c|}
\hline Aspect & $\begin{array}{l}\text { The locations of the } \\
\text { schools }\end{array}$ & $\begin{array}{l}\text { The prospects after } \\
\text { graduation }\end{array}$ & $\begin{array}{l}\text { The correlations of the } \\
\text { disquisitions }\end{array}$ & $\begin{array}{l}\text { The willingness to } \\
\text { contest }\end{array}$ & $\begin{array}{l}\text { The competition } \\
\text { experiences }\end{array}$ \\
\hline Skill & - & $(1)>(2)$ & $(1)>(2)$ & $(1)>(2)$ & $(2)>(1)$ \\
\hline Affection & - & - & (1) $>$ (2) & $(1)>(2)$ & - \\
\hline Cognition & - & - & $(1)>(2)$ & $(1)>(2)$ & - \\
\hline $\begin{array}{l}\text { The integral } \\
\text { learning } \\
\text { efficiency }\end{array}$ & - & $(1)>(2)$ & $(1)>(2)$ & $(1)>(2)$ & - \\
\hline
\end{tabular}

A. The locations of the school: a. in the north; b. in the central region; $c$. in the south;

B. The prospects after graduation: a. enter a higher school; b. seek a job;

C. The correlations of the disquisitions: a. related; b. irrelative;

D. The willingness to contest: $a$. with the willingness to contest; $b$. without the willingness to contest;

E. The competition experiences: a. with the competition experiences; b. without the competition experiences.

1) The Analysis of Variance of Students from Different School Location's Different Learning Outcomes. Students from different school location have little difference in their cognition of 'Skills', 'Affection', 'Cognition', and 'The Overall Learning Outcome'. That shows that students from different school location have similar learning outcomes; students' learning outcomes would not be different because of the school locations.

2) The Analysis of Variance of Students with Different Future Direction after Graduation's Different Learning Outcomes. Students with different future direction after graduation have reached significant differences in 'Skills' aspect. From the outcome of t-test, we can know that students who choose to go for further study after graduation have higher learning outcomes than those who choose to get a job after graduation.

3) The Analysis of Variance of Students with Different Monographic Correlation's Different Learning Outcomes. Students with different monographic correlation have reached significant differences in all 'Skills', 'Affection', and 'Cognition' aspect. Students whose monographic topics are related to energy science education have higher learning outcomes in 'Skills', 'Affection', and 'Cognition' aspect than those whose monographic topics are not related to energy science education. In short, students whose monographic topics are related to energy science education have higher learning outcomes than those whose monographic topics are not related to energy science education.

4) The Analysis of Variance of Students with Different Willingness of Taking Part in Monographic Producing Competition's Different Learning Outcomes. The students, the candidates, show the significant differences of achievement in three aspects - skill, affection, and cognition. The students who are willing to contest reach better achievements than the ones who aren't. Namely, the result of variance analysis of integral learning achievement is at significant level, and it presents the students with participative willingness receive the nicer integral learning achievement than the students without participative willingness.

5) The variance analysis of the students' learning achievements with varied competition experiences. The students with varied competition experiences show the significant differences in the aspect of "skill." T test demonstrates that the students with competition experiences reach the better learning achievements in the aspect of "skill" than the students without competition experiences. As for integral learning efficiency, the result of variance analysis is not significant.

Discuss the students' motivation and learning efficiency of Energy Science and Technology Implementation into project-doing. According to the statistics in researches, the students' motivation and learning efficiency of Energy Science and Technology Implementation into project-doing is significant - correlation coefficient is .01. In addition, the "integral learning motivation" and "integral learning efficiency" in Pearson product-moment correlation coefficient ( $r=844)$ demonstrate that the students reinforce their learning achievements by their learning motivation while Energy Science and Technology implements into project-doing. Thus, the result corresponds with the result of Tsai and Zhang's research [8], [9].

The positive impact of learning motivation on learning achievement. Based on the information from the formal surveys, I gradually underwent the Multiple Regression Analysis - learning motivation as predictor variable and learning achievement as criterion variable - and the result is as follows. The four variables, "career development", "expectations of success", "desire to learning", and "the value of the subjects", have significant predictive power. The multiple correlation coefficient of the four variables and learning efficiency is .850; $\mathrm{R} 2$ is .723; F value of last integral regression test is $529.960(p=.000)$. Therefore, the four predictor variables can explain how the variance of learning achievement is $72.3 \%$ validly. In regression model, the $\beta$ value of the four variables are $.366, .324, .184$, and .077 , and all of the positive numbers illustrate their positive impact on "learning achievement". 


\section{Conclusion And Suggestion}

\section{A. Conclusion}

In the light of the surveys, the statistical data was analyzed through SPSS Packages, and the induced conclusions are as follows.

1) Through Energy Science and Technology Implementation into project-doing, the students who major in Electrical Engineering and Electronic Engineering of public vocational schools get more motivation in the aspect of "expectations of success"; In ROC, the learning motivation in "career development", "desire to learning", "the value of the subjects", and "expectations of success" of the students who major in Electrical Engineering and Electronic Engineering of public vocational schools get the average score meets "compliance". Among the four aspects, "desire to learning" gets the highest score, and it meets "compliance" as well. Hence, Energy Science and Technology Implementation into the project-doing actually impacts the students who major in Electrical Engineering and Electronic Engineering of public vocational schools positively.

2) The suggestion rough Energy Science and Technology Implementation into project-doing, the students reach better learning achievement in cognition aspect. After studying the documents and analyzing the elements, three dimensions, skill, affection and cognition, are made to measure the learning achievement, and the three dimensions meet "compliance". While the students reach best achievement in cognition aspect and worst achievement in skill aspect, the research suggests that project-doing course should be two-to-six credit course. Frankly speaking, the works of project-doing course is brought about by the students' professional knowledge and techniques which are learned and applied in routine during the three years at school; the insufficient credits will lead to the incompleteness of the pieces. Moreover, the upcoming Technological and Vocational Examination must influence the seniors' energy and time into projects, and then it will cause students' worse learning achievement in skill aspect. As for the integral learning achievement, the score is 4.00 and it reveals that students reach fine achievement of learning through Energy Science and Technology Implementation into project-doing.

3) The students with the willingness of "entering a higher school", "doing the project related to Energy Science and Technology Education" and "participating in the project-doing contests" get better learning achievements among the ones came from different background. Through the Energy Science and Technology Implementation into project-doing, various "prospects after graduation", "correlations of the disquisitions", "willingness to contest" and "competition experiences", "integral learning motivation" and "integral learning achievement" differentiate the students' learning motivation significantly. The examination of t-test sample illustrates that: A). The students who are willing to enter higher schools have more motivation than the students who choose to seek jobs after graduation; B). The students do the projects related to Energy Science and Technology Education have more learning motivation than the students who don't. C). The students with the willingness of participating in the project-doing contests have more learning motivation than the students who without.

4) The students with the willingness of "entering a higher school", "doing the project related to Energy Science and Technology Education" and "participating in the project-doing contests" get better learning efficiency among the ones came from different background. In terms of the results of survey analysis, through the Energy Science and Technology Implementation into project-doing, various "prospects after graduation", "correlations of the disquisitions", "willingness to contest" and "competition experiences", "integral learning motivation" and "integral learning achievement" differentiate the students' learning efficiency significantly. The examination of t-test sample illustrates that: A). The students who are willing to enter higher schools get better learning achievements than the students who choose to seek jobs after graduation; B). The students do the projects related to Energy Science and Technology Education get better learning achievements than the students who don't. C). The students with the willingness of participating in the project-doing contests get better learning achievements than the students who without.

5) Through Energy Science and Technology Implementation into project-doing, there are high-positive correlation between the learning motivation and the learning achievement of the students who major in Electrical Engineering and Electronic Engineering of public vocational schools

6) In terms of the product-moment correlation analysis of learning motivation and learning achievement, the correlation coefficient of every aspect and the two integral objects is significant .01,and the "integral learning motivation" and "integral learning achievement" of Pearson product-moment correlation coefficient $(r=.844)$ demonstrates the two objects are high-positive correlation. As for part 5 of chapter 4 , in regression model, learning motivation versus learning efficiency of the $\beta$ value of the four variables are $.366, .324, .184, .077$, and all of the positive numbers illustrate their positive impact on "learning achievement".

\section{B. Suggestion}

Based on the result and discovery of research, the suggestions are for educational administrations and future research.

\section{1) The suggestions for educational administrations}

1) Increase the courses related to Energy Science and Technology Education: while at present no vocational Energy Science and Technology courses are for stimulating the students' motivation and interests, this research uncovers that the students see the subjects as low-value ones. For the reason, increasing the courses 
related to Energy Science and Technology can stimulate the students' learning motivation well.

2) Enhance the training of Energy Science and Technology teacher as seeds: the valid questionnaires manifest students' lower motivation toward the aspect of subject value than other aspects. The average of question 18, I have interest in the project-doing of Energy Science and Technology Education, is 3.72; the average of question 20, I consider the Energy Science and Technology Education project-doing makes me know better about Energy Science and Technology Industry, is 3.64, and the number is lower than integral average, 4.05. The numbers illustrate that the students know little about the courses of Energy Science and Technology Education. Consequently, the suggestions for educational administrations are enhance the training of Energy Science and Technology teacher as seeds, persist in the seeds' making Energy Science and Technology Education blending with courses, and stimulate students' interests in Energy Science and Technology Education. Later, they will read and get further knowledge by themselves, and then they can apply Energy Science and Technology in project-doing courses.

\section{2) The suggestions for future research}

1) Research methods: this research utilizes surveys. So the answers are from respondents' subjective consciousness and whether they are truth or not is unknown. Thus, the suggestion for future researchers is that utilizing the results of experiments can make the research more objective and efficient.

2) Further Studies: The studies of the research are the seniors who major in Electrical Engineering and Electronic Engineering of public senior vocational senior high schools. If it's possible, the future research can set the seniors of 15 branches in public and private vocational schools as studies. Thus, after implementing Energy Science and Technology, by analyzing and comparing the learning motivation and learning achievement of students from different branches, the data will be more representative and complete.

\section{REFERENCES}

[1] Bureau of Energy, Ministry of Economic Affairs. (2011). Energy Statistical Manual of the republic of China. [Online]. Available: http://web3.moeaboe.gov.tw/ECW/populace/content/SubMenu.aspx? menu_id=141

[2] H. S. Su, J. D. Chen, M. M. Lu, Y. M. Chen, J. Chou, and I. J. Wu, Climate Change in Taiwan: Scientific Report 2011, National Science Council.

[3] Environmental Protection Agency. (2013). United Nations Framework Convention on Climate Change and the Kyoto Protocol. [Online]. Available: http://www.epa.gov.tw/ch/aioshow.aspx?busin=7603\&path=10966\&g uid=18e29c81-a3e4-4e8f-b949-4bec3607b674\&lang=zh-tw

[4] Bureau of Energy, Ministry of Economic Affairs. (2011). Energy Statistical Manual of the republic of China. [Online]. Available: http://web3.moeaboe.gov.tw/ECW/populace/content/SubMenu.aspx? menu_id=141

[5] H. K. Lui, "Actively build up low carbon homes - from low-carbon communities towards a low-carbon city, Environmental education and training e-newsletter," no. 38, June, 2010

[6] J. B. Cheng and Y. M. Sung, Energy Education, Energy Report, vol. 5, pp. 23-26, 2009.

[7] Environmental Protection Agency. (2013). Greenhouse gas emissions statistics. [Online]. Available:

http://www.epa.gov.tw/ch/artshow.aspx?busin=12379\&art=20090117 $15443552 \&$ path $=12437$.

[8] M. L. Wu, SPSS operation and application: statistical analysis of survey practice, Wunan, Taipei, 2009.

[9] H. H. Tsai and Y. P. Zhang, "The impact of motivation on its learning effectiveness, moderating in leadership behavior," Chinese Journal of Management, no. 8, pp. 1-17, 2007.

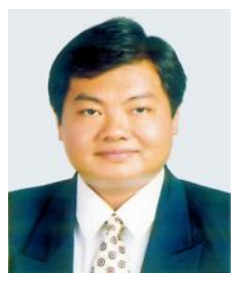

Fang-Pin Lai received M.S. degree at the Department of Industry Education from National Taiwan Normal University in 1994, and currently he is a doctoral student of the Department of Industrial Education and Technology at National Changhua University of Education (NCUE), Taiwan, R.O.C.

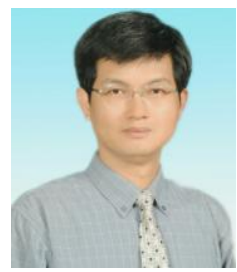

Chin-Wen Liao received both M.S. and Ph.D. in industrial education from National Taiwan Normal University, Taiwan, R.O.C. in 1994 and 2002, respectively. Since August 2011, he has been a professor in Department of Industrial Education and Technology at National Changhua University of Education (NCUE) in Taiwan, R.O.C. He teaches courses in technology and vocational education, energy education, course and teaching, organizational learning. His research interests include technology and vocational education, teacher education, energy education of technology, and learning organization.

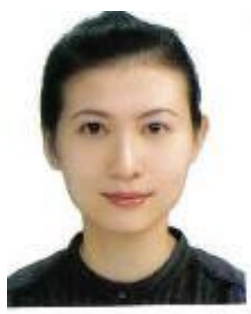

Chia-Ling Shih now is teaching in Mingdao High School in Taichung city, Taiwan and studying in tourism who graduated in EMBA from Providence University in 2012.

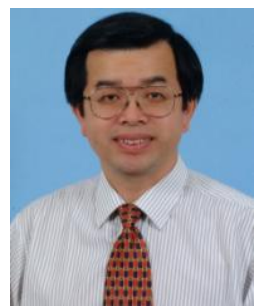

Chin-Chang Wu received M.S. in education from National Changhua University of Education, Taiwan, R.O.C. and Ph.D in Industrial Education and Technology from National Changhua University of Education in 2005. He has been a school principal in Dong- Shing Elementary School, Taiwan, R.O.C. and dealt with administrative affairs of the school. His research interests include leading, technology, and vocational education. 